\title{
Genome-wide association study reveals class I MHC-restricted T cell-associated molecule gene (CRTAM) variants interact with vitamin D levels to affect asthma exacerbations
}

\section{Citation}

Du, Rose, Augusto A. Litonjua, Kelan G. Tantisira, Jessica Lasky-Su, Shamil R. Sunyaev, Barbara J. Klanderman, Juan C. Celedón, Lydiana Avila, Manuel E. Soto-Quiros, and Scott T. Weiss. 2012. Genome-wide association study reveals class I MHC-restricted T cell-associated molecule gene (CRTAM) variants interact with vitamin $D$ levels to affect asthma exacerbations. Journal of Allergy and Clinical Immunology 129, no. 2: 368-373.e5. doi:10.1016/j.jaci.2011.09.034.

\section{Published Version}

doi:10.1016/j.jaci.2011.09.034

\section{Permanent link}

http://nrs.harvard.edu/urn-3:HUL.InstRepos:27003505

\section{Terms of Use}

This article was downloaded from Harvard University's DASH repository, and is made available under the terms and conditions applicable to Other Posted Material, as set forth at http:// nrs.harvard.edu/urn-3:HUL.InstRepos:dash.current.terms-of-use\#LAA

\section{Share Your Story}

The Harvard community has made this article openly available.

Please share how this access benefits you. Submit a story.

\section{Accessibility}




\title{
Genome-wide association study reveals class I MHC-restricted T cell-associated molecule gene (CRTAM) variants interact with vitamin D levels to affect asthma exacerbations
}

\author{
Rose Du, MD, PhD a,b,c, Augusto A. Litonjua, MD ${ }^{a, c, d}$, Kelan G. Tantisira, MD \\ Lasky-Su, ScD ${ }^{a, c}$, Shamil R. Sunyaev, PhD ${ }^{c}$, Barbara J. Klanderman, PhD ${ }^{a, c}$, Juan C. \\ Celedón, MD, DrPH ${ }^{a, e}$, Lydiana Avila, MD ${ }^{\dagger}$, Manuel E. Soto-Quiros, MD, PhD ${ }^{f}$, and Scott T. \\ Weiss, MD ${ }^{a, c, d}$ \\ aChanning Laboratory, Brigham and Women's Hospital, Boston \\ bDepartment of Neurosurgery, Brigham and Women's Hospital, Boston \\ cHarvard Medical School, Boston \\ ${ }^{d}$ Center for Genomic Medicine, Brigham and Women's Hospital, Boston \\ eDivision of Pediatric Pulmonary Medicine, Allergy and Immunology, Department of Pediatrics, \\ Children's Hospital of UPMC, University of Pittsburgh School of Medicine \\ fDivision of Pediatric Pulmonology, Hospital Nacional de Niños, San José
}

\begin{abstract}
Background-It has recently been shown that vitamin D deficiency can increase asthma development and severity and that variations in vitamin D receptor genes are associated with asthma susceptibility.
\end{abstract}

Objective-We sought to find genetic factors that might interact with vitamin D levels to affect the risk of asthma exacerbation. Methods: We conducted a genome-wide study of gene-vitamin D interaction on asthma exacerbations using population-based and family-based approaches on 403 subjects and trios from the Childhood Asthma Management Program. Twenty-three polymorphisms with significant interactions were studied in a replication analysis in 584 children from a Costa Rican cohort. Results: We identified 3 common variants in the class I MHCrestricted T cell-associated molecule gene (CRTAM) that were associated with an increased rate of asthma exacerbations based on the presence of a low circulating vitamin $\mathrm{D}$ level. These results were replicated in a second independent population (unadjusted combined interaction, $P=.00028-$. 00097; combined odds ratio, 3.28-5.38). One variant, rs2272094, is a nonsynonymous coding polymorphism of CRTAM. Functional studies on cell lines confirmed the interaction of vitamin D and rs2272094 on CRTAM expression. CRTAM is highly expressed in activated human $\mathrm{CD}^{+}$ and natural killer $\mathrm{T}$ cells, both of which have been implicated in asthmatic patients.

Conclusion-The findings highlight an important gene-environment interaction that elucidates the role of vitamin $\mathrm{D}$ and $\mathrm{CD} 8^{+}$and natural killer T cells in asthma exacerbation in a genome-wide

(C) 2011 American Academy of Allergy, Asthma \& Immunology

Corresponding author: Rose Du, MD, PhD, Department of Neurosurgery, Brigham and Women's Hospital, 75 Francis St, Boston, MA 02115.rdu@ partners.org. 0091-6749/\$36.00.

Disclosure of potential conflict of interest: A. A. Litonjua, K. G. Tantisira, S. R. Sunyaev, B. J. Klanderman, and M. E. Soto-Quiros receive research support from the National Institutes of Health. J. C. Celedón is on the advisory board for Genentech, receives research support from the NIH, and receives royalties from UpToDate. The rest of the authors declare that they have no relevant conflicts of interest. 
gene-environment interaction study that has been replicated in an independent population. The results suggest the potential importance of maintaining adequate vitamin D levels in subsets of high-risk asthmatic patients.

\section{Keywords}

Gene-environment interaction; genome-wide association study; vitamin D; asthma exacerbation

Asthma, a major public health problem affecting more than 300 million persons worldwide, ${ }^{1}$ is a complex disease affected by many interacting genetic and environmental factors. We and others have shown that maternal dietary intake of vitamin D during pregnancy is associated with lower risk of recurrent wheeze, asthma, and allergy in early life, ${ }^{2-6}$ and reduced vitamin $\mathrm{D}$ levels are associated with an increased risk of severe disease exacerbations in children with asthma. ${ }^{1,7}$ Specifically, the population attributable risk of asthma incidence caused by vitamin D deficiency in pregnancy is about $40 \%$ of all cases, ${ }^{2}$ and insufficient vitamin D was associated with a higher odds of any hospitalization or emergency department visit over 4 years (odds ratio [OR], 1.5; 95\% CI, 1.1-1.9). ${ }^{7}$ It has also been shown that vitamin D deficiency is associated with more severe exercise-induced asthma and loss of asthma control. ${ }^{8,9}$ However, the involved mechanisms are unknown. One link between asthma and vitamin D levels is the inflammatory response. It has been suggested that vitamin $\mathrm{D}$ might be involved in the control of asthma exacerbation by reversing steroid resistance in $\mathrm{CD} 4^{+} \mathrm{T}$ cells. ${ }^{1}$ Although the role of $\mathrm{CD} 4^{+} \mathrm{T}_{\mathrm{H}} 2$ lymphocytes ${ }^{10}$ in asthmatic patients is well known, that of $\mathrm{CD} 8^{+} \mathrm{T}$ cells is incompletely understood. Vitamin $\mathrm{D}$ has been shown to be involved with the immune response through its effects on $\mathrm{CD} 8^{+} \mathrm{T}$ cell-mediated cytotoxicity ${ }^{11}$ and the development of natural killer (NK) T cells, ${ }^{12}$ thereby suggesting a link between vitamin $\mathrm{D}$ and asthma through $\mathrm{CD} 8^{+}$and NKT cells.

Although a number of human studies have shown that vitamin D insufficiency is associated with increased asthma severity, ${ }^{1,2}$ others have shown the opposite ${ }^{13}$ One reason for these inconsistencies might be the effect of vitamin $\mathrm{D}$ interacting with genes in different pathways involved in asthma. Although variants in the vitamin D receptor gene ${ }^{14,15}$ and vitamin D pathway genes ${ }^{16}$ are associated with asthma susceptibility, the genetic pathways by which vitamin D influences asthma exacerbations is unknown. Therefore the evaluation of the role of genetic variation in the context of vitamin $\mathrm{D}$ as an environmental factor as it relates to asthma outcomes is warranted and has the potential not only to predict the subset of highrisk patients but also to suggest a possible therapy in this group of patients.

\section{METHODS}

\section{Study populations}

The gene-environment interaction of vitamin $\mathrm{D}$ levels on asthma exacerbation was examined by using the cohort from the Childhood Asthma Management Program (CAMP) study, a multicenter, randomized, double-blind clinical trial testing the effects of anti-inflammatory medications in children with mild-to-moderate asthma over a period of 4 to 6 years. This study was limited to non-Hispanic white participants to minimize population stratification. The study methodology and trial design have been described elsewhere. ${ }^{17}$ The CAMP study consisted of 1041 children. Of those, 422 met the criteria for non-Hispanic white race and availability of DNA for genotyping. Illumina Infinium II 550K SNP Chips (Illumina, Inc, San Diego, Calif) were genotyped in 422 nuclear families. Of those 422 trios, 9 have failed genotyping, leaving 403 families for analysis. Of these 403 probands, 395 have vitamin D level data. Vitamin D levels were obtained at the time of randomization and were dichotomized as low ( $\leq 30 \mathrm{ng} / \mathrm{mL}$ ) or high (>30 ng/mL). Asthma exacerbation is defined as 
having had emergency department visits or hospitalizations within the first year of randomization.

Replication was done with index cases from a family-based genetic study of asthma in Costa Rica. Subject recruitment and study procedures have been published. ${ }^{1}$ Briefly, the Costa Rican study consisted of questionnaires sent to 13,125 children. Of these, 616 unrelated children were enrolled in the study who had a high likelihood of having at least 6 greatgrandparents born in the Central Valley of Costa Rica. A single measurement of vitamin D levels was obtained in all subjects. Of the 616 children, we were able to obtain genotypes in 584. Asthma exacerbation is defined as having had emergency department visits or hospitalizations in the year before the study.

\section{Statistical methodology}

The gene-environment interaction was analyzed by using both family-based and populationbased methods. Family-based association testing was done through PBAT (version 3.5). ${ }^{18}$ The population-based association study in which only probands are considered uses the generalized linear model (glm package in the R software environment) with the binomial distribution as the link function and examines the test statistic of the multiplicative interaction term. ${ }^{19}$ Association analyses were performed by using the additive genetic model. Age, sex, and baseline $\mathrm{FEV}_{1}$ were used as covariates. The family-based association test of gene-environment interaction is based on the family trio design and sums over parental mating types of the sample covariance among the affected offspring. ${ }^{20}$ The statistical inference is based on the permutation distribution of the test statistic under the null hypothesis. Single nucleotide polymorphisms (SNPs) were filtered for those that contain more than 10 informative families, those in which the effects of both the main genetic factor and the interaction are the same in both the population-based and family-based analyses, and those with minor allele frequencies of greater than 0.01. Informative families are those having at least 1 parent contributing to the variance of the offspring during transmission (ie, those with $\geq 1$ heterozygous parent). ${ }^{21}$ Allelic ORs were obtained by using the epitools package in the $\mathrm{R}$ environment and calculated by using the unconditional maximum likelihood estimation. In assessing joint evidence for association, population-based $P$ values were combined by using the Liptak-Stouffer method. The summary ORs from the CAMP and Costa Rican cohorts were calculated by using the Mantel-Haenszel approach (rmeta package in the R software environment).

Linkage disequilibrium was assessed by using HAPLOVIEW ${ }^{22}$ and PLINK version 1.07. ${ }^{23}$ SNPs with $r^{2}$ values of greater than 0.8 were considered to be in linkage disequilibrium. Motifs in the protein structures were identified by using the Eukaryotic Linear Motif resource (http://elm.eu.org). Pupasuite2 (http://pupasuite.bioinfo.cipf.es) was used to identify triplex-forming oligo-nucleotide target sequences (TTSs). Exonic splicing enhancerbinding sites were predicted with SNPinfo ${ }^{24}$ and RESCUE ESE. ${ }^{25}$

\section{Genotyping and quality control}

Genome-wide SNP genotyping was performed in the CAMP sample by Illumina, Inc, on the HumanHap550v3 BeadChip. Genotype reproducibility was assessed by analyzing 4 subjects whose studies were repeated once on each of the 14 genotyping plates; all replicates had at least $99.8 \%$ concordance.

There were 561,466 SNPs on the HumanHap550v3 BeadChip. SNPs were removed for the following reasons: (1) 6,257 markers were removed because of low Illumina clustering scores; (2) 1,379 markers were removed because their flanking sequences did not map to a unique position on the $h g 17$ reference genome sequence; (3) 3,790 markers were removed 
because they were monomorphic in our sample; and (4) 2,445 markers were removed because of 5 or more parent-child genotype inconsistencies. We used PLINK ${ }^{23}$ for further quality control of the remaining markers. All markers had a greater than $90 \%$ genotyping completion rate, with an average completion rate of greater than 99\%. Although no HardyWeinberg equilibrium filtering was done in the initial quality control, Hardy-Weinberg equilibrium was assessed in the SNPs that were selected for replication. Of the 561,466 markers present on the BeadChip, 547,645 (97.54\%) passed these quality control metrics. A total of 534,290 of these were autosomal markers and therefore were used in the analysis. One thousand one hundred sixty-nine CAMP subjects were successfully genotyped, including 403 probands and their parents. The average genotyping completion rate for each subject was $99.8 \%$.

We genotyped 23 SNPs identified from the screening stage in CAMP in the Costa Rican population. The average call rate was $99.33 \%$ and the average completion rate was $99.5 \%$ for the SNPs that passed the quality control filters. The Hardy-Weinberg equilibrium $P$ value was calculated for each SNP to identify possible deviations that might be attributed to genotyping errors or assay design. SNPs were chosen based on low $P$ values in both population-based and family-based analyses and potential biological relevance. SNPs were genotyped with an Illumina BeadStation 500G and with a Sequenom MassArray matrixassisted laser desorption/ionization time-of-flight mass spectrometer (Sequenom, Inc, San Diego, Calif). A semiautomated primers design program (SpectroDESIGNER; Sequenom, Inc) was used for Sequenom. Each genotype was checked for percentage completion rates.

\section{Class I MHC-restricted T cell-associated molecule gene expression}

EBV-immortalized B-lymphocyte cell lines from 20 CAMP subjects were cultured. There were 128 CAMP subjects with immortalized B cells and genome-wide genotype data. Of the 128 subjects, 64 were homozygous for the major allele and 15 were homozygous for the minor allele of the rs2272094 nonsynonymous SNP. From these, 10 cell lines of each homozygous class were selected at random for the vitamin D stimulation expression study. For each cell line, there were 4 sets consisting of 1 million cells each. Two sets were treated with $1 \mu \mathrm{mol} / \mathrm{L}$ 1a,25-dihydroxyvitamin $\mathrm{D}_{3}$ dissolved in ethanol, and 2 sets were used as controls (ethanol only). Cells were harvested at 72 hours after treatment. RNA was extracted with the Stratagene Absolutely RNA Miniprep kit (Stratagene, La Jolla, Calif), according to the manufacturer's standard protocol. RNA quality was checked with an Agilent 2100 BioAnalyzer (Agilent Technologies, Santa Clara, Calif) and showed minimal evidence of degradation, with 28S:16S ratios approaching 2.0. RNA was converted to cDNA by using the Applied Biosystems TaqMan Reverse Transcription Reagents kit (Applied Biosystems, Foster City, Calif) and $500 \mathrm{ng}$ of RNA per sample. RT-PCR quantification of the class I MHC-restricted T cell-associated molecule gene (CRTAM) was performed in triplicate on each sample by using Applied Biosystems TaqMan gene expression assays, according to the manufacturer's standard protocol. The peptidylprolyl isomerase A gene (PPIA) was used as a normalization control. The comparative cycle threshold method was used for determining relative transcript abundance.

\section{RESULTS}

We performed a genome-wide study to investigate the interaction of genetic variants with circulating vitamin D levels on the risk of asthma exacerbations. Our study was designed to perform 2 valid statistical tests on the CAMP population to identify the most robust SNPs that would then be validated in an independent population (Table I and see Fig E1 in this article's Online Repository at www.jacionline.org). The 2 statistical tests were achieved by performing both family-based and population-based analyses in 403 trios from CAMP using 
534,290 SNPs. Replication was performed on 584 children from a Costa Rican study using 23 SNPs screened from the CAMP analysis.

Population analyses were performed in the CAMP probands and subsequently compared with family-based statistical analyses (family-based association testing) by using a subset of CAMP probands and their parents. SNPs with low $P$ values $(P<.01)$ in both analyses and in which the directions of the main genetic effect and interaction were the same in both analyses were considered for replication. The family-based analyses are robust against population stratification ${ }^{21}$ and add a self-consistency check and credibility to the populationbased findings, even though the $P$ values do not reach genome-wide significance after correction for multiple testing given the moderate size of the CAMP population. However, the combined ranking of the family-based and population-based analyses highlighted potential candidate SNPs that were used for replication in the Costa Rican cohort. Of the SNPs fitting the above criteria by using the additive model, 23 were chosen for replication (Table II). Of those, 9 were not in linkage disequilibrium with any of the other SNPs.

In the Costa Rican replication population population-based analysis was performed in the index children. A combined Liptak-Stouffer $P$ value was then obtained from the populationbased results of the CAMP and Costa Rican studies. Three of the 23 SNPs shown in Table II were found to be nominally significant and are associated with the CRTAMgene, which is located at 11q24.1 (Fig 1 and see Table E1 in this article's Online Repository at www.jacionline.org). Notably, in both populations subjects homozygous for the minor allele for these 3 variants who have low vitamin D levels demonstrated an increased likelihood of exacerbations. Conversely, high vitamin D levels appeared to be protective for the same variants. The combined Mantel-Haenszel OR of the CAMP and Costa Rican cohorts for asthma exacerbation for the homozygous minor allele under low versus high vitamin D levels were 4.44, 3.28, and 5.38 for rs 2272094, rs2140151, and rs7941607, respectively, compared with $0.42,0.43$, and 0.46 , respectively, for the homozygous major allele (Fig 2). Linkage disequilibrium for the top 3 SNPs is consistent across both populations (see Fig E2 in this article's Online Repository at www.jacionline.org).

One of the 3 SNPs, rs2272094, is a nonsynonymous SNP causing an amino acid change from K (Lys) to R (Arg). To confirm the functional effects of the interaction of rs2272094 variants with vitamin D levels, we performed quantitative PCR studies on 10 cell lines homozygous for the major allele and 10 cell lines homozygous for the minor allele in the presence and absence of vitamin D. We noted allele-specific evidence for interaction between vitamin D administration and CRTAM expression (Fig 3). The difference in CRTAM expression in the presence of vitamin D was significantly different for the homozygous minor allele group $(P=.004)$ but not for the homozygous major allele group ( $P$ $=.08)$. In addition, the variation in $C R T A M$ expression explained $\left(I^{2}\right)$ by the genotype was $7.6 \%$ in the presence of vitamin D compared with $0.03 \%$ with no vitamin $\mathrm{D}$. This provides functional evidence for a gene-environment interaction of rs2272094 and vitamin D. However, further functional studies of $C R T A M$ will need to be done to determine the exact mechanism by which $C R T A M$ affects the relationship between vitamin $\mathrm{D}$ and asthma exacerbation.

\section{DISCUSSION}

Using both a population-based and family-based approach, we have a nonsynonymous SNP, rs2272094, associated with $C R T A M$ that was replicated in an independent population. The risk of asthma exacerbation in patients homozygous in the minor allele of rs2272094 for low versus high vitamin D levels was an OR of 7.5 (95\% CI, 0.93-60.43) in the CAMP population and 3.52 (95\% CI, 0.69-18.05) in the Costa Rican replication population, with an 
overall OR of 4.4 (95\% CI, 1.19-16.58) and a combined attributable risk of 56\%. Genomewide searches for gene-environment interactions, including those involving asthma, ${ }^{26}$ have been largely unsuccessful, and to our knowledge, none have been successfully replicated. That our result was consistent in both a population-based approach and a family-based approach and was replicated in an independent population for an interaction SNP suggests that this is a functional and causal SNP.

Viral infections are a major cause of asthma exacerbations, ${ }^{27}$ and vitamin D deficiency has been shown to be associated with increased susceptibility to viral respiratory tract infections. $^{28}$ Therefore prevention of viral infections might be one mechanism for vitamin D's involvement. Numbers of activated $\mathrm{CD}^{+} \mathrm{T}$ cells in peripheral blood are increased during viral respiratory tract infections, ${ }^{29}$ whereas NK activity is enhanced in acute asthma exacerbations. ${ }^{30}$ This implies a link between $\mathrm{CD}^{+}$and NKT cells and asthma exacerbation. Because vitamin D is known to up-regulate proteins that have antiviral properties, ${ }^{31}$ have an inhibitory effect on $\mathrm{CD}^{+} \mathrm{T}$ cell-mediated cytotoxicity, ${ }^{11}$ and are required for the normal function of NKT cells, ${ }^{12}$ it is possible that one mechanism by which vitamin D prevents asthma exacerbations is through $\mathrm{CD}^{+}$and NKT cells during viral infections.

CRTAM expression is restricted to class I MHC T cells, including CD8 ${ }^{+}$and NKT cells. It is also one of the most highly expressed surface markers of activated human $\mathrm{CD}^{+}$and NKT cells. ${ }^{32}$ CRTAM binds to Necl-2 on antigen-presenting cells and has been shown to promote cytotoxicity of NKT cells and IFN- $\gamma$ and IL-22 secretion of $\mathrm{CD}^{+} \mathrm{T}$ cells. ${ }^{33}$ It has also been shown to regulate the immune response through the retention of $\mathrm{CD}^{+} \mathrm{T}$ cells within lymph nodes. ${ }^{34}$ Moreover, the lungs are one of the tissues with the highest expression of $C R T A M,^{32}$ and it is thus plausible that variants in CRTAMinteract with vitamin D on asthma exacerbations, perhaps through prevention of viral illnesses. It also suggests a mechanism by which $\mathrm{CD}^{+} \mathrm{T}$ and NKT cells contribute to asthma exacerbation through IL-22 and IFN- $\gamma$.

There are a number of potential ways in which rs2272094 might meaningfully affect CRTAM function and expression in the context of altered vitamin D levels. Using the Eukaryotic Linear Motif resource for motif identification, we found that the rs2272094 change in amino acid from $\mathrm{K}$ to $\mathrm{R}$ corresponds to a change in motif from the KEN box to a proprotein convertase cleavage site, thereby potentially promoting the stabilization of the CRTAM protein.

Second, rs2272094 corresponds to the first base in the consensus sequence for binding of steroidogenic factor-1 (5' -AA GGTCA-3'; see Fig E3 in this article's Online Repository at www.jacionline.org), which has been shown to play a role in ste-roidogenesis. ${ }^{35}$

Steroidogenic factor- 1 is an orphan steroid receptor shown to regulate the transcription of P450 steroid hydroxylase genes. ${ }^{35}$ Because members of the cytochrome P450 superfamily are key enzymes in vitamin D metabolism, ${ }^{36}$ this suggests a possible mechanism by which CRTAM might be linked with vitamin D metabolism. In addition, rs2272094 is part of a TTS, 5' -GGAAGAAAGG-3'. TTSs have the largest concentration in regulatory regions and are thought to contribute to gene expression. ${ }^{37}$ Triplex formation can lead to modulation in gene expression, transcription, protein binding, and targeting for DNA damage. A variant in this region might therefore have a number of functional consequences.

Finally, the minor allele in rs2272094 results in a change in an exonic splicing enhancerbinding site, AGAGAG, to one that is not, AGAAAG, which could prevent an entire exon from being transcribed.

Although it was the SNPs associated with CRTAM that replicated with nominal significance, it is interesting to note that 11 of the 23 SNPs examined were associated with 
the phospholipase C-like 1 gene (PLCL1). PLCL1 did not replicate in the Costa Ri-can cohort, however. Nevertheless, it would be interesting to examine PLCL1 in future replication studies.

One limitation in this current analysis is the slight difference in the phenotype in the 2 populations. In CAMP the phenotype is severe exacerbations resulting in either emergency department visits or hospitalizations in the year after entry into the trial. In contrast, in the Costa Rican study the phenotype is either emergency department visits or hospitalizations in the past year. To the extent that prior exacerbations predict future exacerbations, ${ }^{38} \mathrm{we}$ believe that this limitation does not invalidate our replication results.

Another limitation is our moderate sample size. The small effects of gene-environment interactions are difficult to detect and even more difficult to replicate. Although a small number of studies have demonstrated gene-environment interaction through candidate SNP studies, only a few have done so through a genome-wide search, ${ }^{39-41}$ and to our knowledge, none have been replicated. Although we were able to achieve nominal significance and replication, a larger sample size in future studies will enable us to achieve genome-wide significance.

In summary, our genome-wide environment interaction study has identified a nonsynonymous variant in CRTAM, rs2272094, which interacts with circulating vitamin D levels in asthma exacerbation in children. The functionality of this variant is supported by gene expression studies and motif and sequence analyses. The association of CRTAM with $\mathrm{CD}^{+}$and NKT cells suggests biologically plausible mechanisms behind the role of these cells and vitamin D on asthma exacerbations in association with viral infections. These findings suggest a means by which asthma exacerbations might be prognosticated based on genotype and vitamin D levels, as well as a potential therapeutic intervention in a subset of the genotypically high-risk population.

\section{Supplementary Material}

Refer to Web version on PubMed Central for supplementary material.

\section{Acknowledgments}

We thank Simin Niu for the gene expression studies.

Supported by National Institutes of Health (NIH) grants R21HL089842 and R01HL092197. We acknowledge the Childhood Asthma Management Program (CAMP) investigators and research team, supported by the National Heart, Lung, and Blood Institute (NHLBI), for collection of CAMP Genetic Ancillary Study data. All work on data collected from the CAMP Genetic Ancillary Study was conducted at the Channing Laboratory of the Brigham and Women's Hospital under appropriate CAMP policies and human subjects' protections. The CAMP Genetics Ancillary Study is supported by U01 HL075419, U01 HL65899, P01 HL083069, R01 HL086601, and T32 HL07427 from the NHLBI/NIH.

\section{Abbreviations used}

$\begin{array}{ll}\text { CAMP } & \text { Childhood Asthma Management Program } \\ \text { CRTAM } & \text { Class I MHC-restricted T cell-associated molecule gene } \\ \text { OR } & \text { Odds ratio } \\ \text { PLCL1 } & \text { Phospholipase C-like 1 gene } \\ \text { SNP } & \text { Single nucleotide polymorphism }\end{array}$




\section{References}

1. Brehm JM, Celedon JC, Soto-Quiros ME, Avila L, Hunninghake GM, Forno E, et al. Serum vitamin D levels and markers of severity of childhood asthma in Costa Rica. Am J Respir Crit Care Med. 2009; 179:765-71. [PubMed: 19179486]

2. Litonjua AA, Weiss ST. Is vitamin D deficiency to blame for the asthma epidemic? J Allergy Clin Immunol. 2007; 120:1031-5. [PubMed: 17919705]

3. Devereux G, Litonjua AA, Turner SW, Craig LC, McNeill G, Martindale S, et al. Maternal vitamin D intake during pregnancy and early childhood wheezing. Am J Clin Nutr. 2007; 85:853-9. [PubMed: 17344509]

4. Camargo CA Jr, Rifas-Shiman SL, Litonjua AA, Rich-Edwards JW, Weiss ST, Gold DR, et al. Maternal intake of vitamin D during pregnancy and risk of recurrent wheeze in children at $3 \mathrm{y}$ of age. Am J Clin Nutr. 2007; 85:788-95. [PubMed: 17344501]

5. Erkkola M, Kaila M, Nwaru BI, Kronberg-Kippila C, Ahonen S, Nevalainen J, et al. Maternal vitamin D intake during pregnancy is inversely associated with asthma and allergic rhinitis in 5year-old children. Clin Exp Allergy. 2009; 39:875-82. [PubMed: 19522996]

6. Miyake Y, Sasaki S, Tanaka K, Hirota Y. Dairy food, calcium and vitamin D intake in pregnancy, and wheeze and eczema in infants. Eur Respir J. 2010; 35:1228-34. [PubMed: 19840962]

7. Brehm JM, Schuemann B, Fuhlbrigge AL, Hollis BW, Strunk RC, Zeiger RS, et al. Serum vitamin D levels and severe asthma exacerbations in the Childhood Asthma Management Program study. J Allergy Clin Immunol. 2010; 126:52-8. e5. [PubMed: 20538327]

8. Chinellato I, Piazza M, Sandri M, Peroni D, Piacentini G, Boner AL. Vitamin D serum levels and markers of asthma control in Italian children. J Pediatr. 2011; 158:437-41. [PubMed: 20870246]

9. Chinellato I, Piazza M, Sandri M, Peroni DG, Cardinale F, Piacentini GL, et al. Serum vitamin D levels and exercise-induced bronchoconstriction in children with asthma. The Eur Respir J. 2011; 37:1366-70.

10. Betts RJ, Kemeny DM. CD8+ T cells in asthma: friend or foe? Pharmacol Ther. 2009; 121:123-31. [PubMed: 18940198]

11. Meehan MA, Kerman RH, Lemire JM. 1,25-Dihydroxyvitamin D3 enhances the generation of nonspecific suppressor cells while inhibiting the induction of cytotoxic cells in a human MLR. Cell Immunol. 1992; 140:400-9. [PubMed: 1531943]

12. Yu S, Cantorna MT. The vitamin D receptor is required for iNKT cell development. Proc Natl Acad Sci U S A. 2008; 105:5207-12. [PubMed: 18364394]

13. Wjst M. The vitamin D slant on allergy. Pediatr Allergy Immunol. 2006; 17:477-83. [PubMed: 17014620]

14. Raby BA, Lazarus R, Silverman EK, Lake S, Lange C, Wjst M, et al. Association of vitamin D receptor gene polymorphisms with childhood and adult asthma. Am J Respir Crit Care Med. 2004; 170:1057-65. [PubMed: 15282200]

15. Poon AH, Laprise C, Lemire M, Montpetit A, Sinnett D, Schurr E, et al. Association of vitamin D receptor genetic variants with susceptibility to asthma and atopy. Am J Respir Crit Care Med. 2004; 170:967-73. [PubMed: 15282199]

16. Bosse Y, Lemire M, Poon AH, Daley D, He JQ, Sandford A, et al. Asthma and genes encoding components of the vitamin D pathway. Respir Res. 2009; 10:98. [PubMed: 19852851]

17. The Childhood Asthma Management Program Research Group. Long-term effects of budesonide or nedocromil in children with asthma. N Engl J Med. 2000; 343:1054-63. [PubMed: 11027739]

18. Laird NM, Horvath S, Xu X. Implementing a unified approach to family-based tests of association. Genet Epidemiol. 2000; 19(suppl 1):S36-42. [PubMed: 11055368]

19. R Development Core Team. R: a language and environment for statistical computing. Vienna, Austria: R Foundation for Statistical Computing; 2008. Available at: http://www.R-project.org 
20. Lake SL, Lyon H, Tantisira K, Silverman EK, Weiss ST, Laird NM, et al. Estimation and tests of haplotype-environment interaction when linkage phase is ambiguous. Hum Hered. 2003; 55:5665. [PubMed: 12890927]

21. Laird NM, Lange C. Family-based designs in the age of large-scale gene-association studies. Nat Rev Genet. 2006; 7:385-94. [PubMed: 16619052]

22. Barrett JC, Fry B, Maller J, Daly MJ. Haploview: analysis and visualization of LD and haplotype maps. Bioinformatics. 2005; 21:263-5. [PubMed: 15297300]

23. Purcell S, Neale B, Todd-Brown K, Thomas L, Ferreira MA, Bender D, et al. PLINK: a tool set for whole-genome association and population-based linkage analyses. Am J Hum Genet. 2007; 81:559-75. [PubMed: 17701901]

24. Xu Z, Taylor JA. SNPinfo: integrating GWAS and candidate gene information into functional SNP selection for genetic association studies. Nucleic Acids Res. 2009; 37(Web Server issue):W600-5. [PubMed: 19417063]

25. Fairbrother WG, Yeo GW, Yeh R, Goldstein P, Mawson M, Sharp PA, et al. RESCUE-ESE identifies candidate exonic splicing enhancers in vertebrate exons. Nucleic Acids Res. 2004; 32(Web Server issue):W187-90. [PubMed: 15215377]

26. Ege MJ, Strachan DP, Cookson WO, Moffatt MF, Gut I, Lathrop M, et al. Gene-environment interaction for childhood asthma and exposure to farming in Central Europe. J Allergy Clin Immunol. 2011; 127:138-44. e1-4. [PubMed: 21211648]

27. Busse WW, Lemanske RF Jr, Gern JE. Role of viral respiratory infections in asthma and asthma exacerbations. Lancet. 2010; 376:826-34. [PubMed: 20816549]

28. Walker VP, Modlin RL. The vitamin D connection to pediatric infections and immune function. Pediatr Res. 2009; 65:106R-13R.

29. Heidema J, Rossen JW, Lukens MV, Ketel MS, Scheltens E, Kranendonk ME, et al. Dynamics of human respiratory virus-specific $\mathrm{CD} 8+\mathrm{T}$ cell responses in blood and airways during episodes of common cold. J Immunol. 2008; 181:5551-9. [PubMed: 18832713]

30. Umetsu DT, DeKruyff RH. A role for natural killer T cells in asthma. Nat Rev Immunol. 2006; 6:953-8. [PubMed: 17068504]

31. Wang TT, Nestel FP, Bourdeau V, Nagai Y, Wang Q, Liao J, et al. Cutting edge: 1,25dihydroxyvitamin D3 is a direct inducer of antimicrobial peptide gene expression. J Immunol. 2004; 173:2909-12. [PubMed: 15322146]

32. Patino-Lopez G, Hevezi P, Lee J, Willhite D, Verge GM, Lechner SM, et al. Human class-I restricted $\mathrm{T}$ cell associated molecule is highly expressed in the cerebellum and is a marker for activated NKT and CD8+ T lymphocytes. J Neuroimmunol. 2006; 171:145-55. [PubMed: 16300832]

33. Boles KS, Barchet W, Diacovo T, Cella M, Colonna M. The tumor suppressor TSLC1/NECL-2 triggers NK-cell and CD8+ T-cell responses through the cell-surface receptor CRTAM. Blood. 2005; 106:779-86. [PubMed: 15811952]

34. Takeuchi A, Itoh Y, Takumi A, Ishihara C, Arase N, Yokosuka T, et al. CRTAM confers late-stage activation of CD8+ T cells to regulate retention within lymph node. J Immunol. 2009; 183:4220-8. [PubMed: 19752223]

35. Parker KL. The roles of steroidogenic factor 1 in endocrine development and function. Mol Cell Endocrinol. 1998; 140:59-63. [PubMed: 9722169]

36. Sakaki T, Kagawa N, Yamamoto K, Inouye K. Metabolism of vitamin D3 by cytochromes P450. Front Biosci. 2005; 10:119-34. [PubMed: 15574355]

37. Duca M, Vekhoff P, Oussedik K, Halby L, Arimondo PB. The triple helix: 50 years later, the outcome. Nucleic Acids Res. 2008; 36:5123-38. [PubMed: 18676453]

38. McCarren M, McDermott MF, Zalenski RJ, Jovanovic B, Marder D, Murphy DG, et al. Prediction of relapse within eight weeks after an acute asthma exacerbation in adults. J Clin Epidemiol. 1998; 51:107-18. [PubMed: 9474071]

39. Sabatti C, Service SK, Hartikainen AL, Pouta A, Ripatti S, Brodsky J, et al. Genome-wide association analysis of metabolic traits in a birth cohort from a founder population. Nat Genet. 2009; 41:35-46. [PubMed: 19060910] 
40. Sonuga-Barke EJ, Lasky-Su J, Neale BM, Oades R, Chen W, Franke B, et al. Does parental expressed emotion moderate genetic effects in ADHD? An exploration using a genome wide association scan. Am J Med Genet B Neuropsychiatr Genet. 2008; 147B:1359-68. [PubMed: 18846501]

41. Zhu W, Cho K, Chen X, Zhang M, Wang M, Zhang H. A genome-wide association analysis of Framingham Heart Study longitudinal data using multivariate adaptive splines. BMC Proc. 2009; 3(suppl 7):S119. [PubMed: 20017984] 


\section{Clinical implications}

The association of variants of $C R T A M$ with asthma exacerbation suggests the potential importance of maintaining adequate vitamin $\mathrm{D}$ levels in subsets of high-risk asthmatic patients. 
CAMP, rs7941607

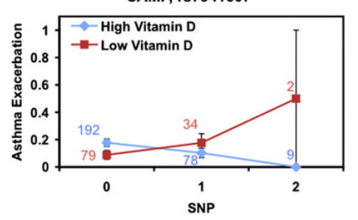

Costa Rica, rs 7941607

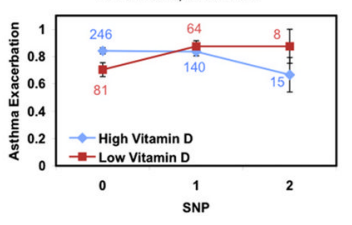

CAMP, rs2272094

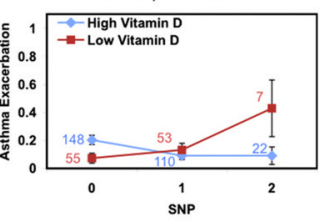

Costa Rica, rs2272094

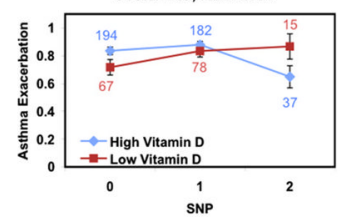

CAMP, rs2140151

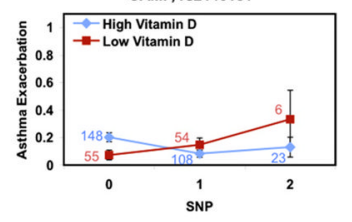

Costa Rica, rs2140151

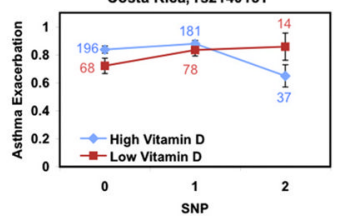

FIG 1.

Association of $C R T A M$ genotype with rates of asthma exacerbation as stratified by high ( $>30 \mathrm{ng} / \mathrm{mL}$ ) versus low ( $\leq 30 \mathrm{ng} / \mathrm{mL}$ ) vitamin D levels in the CAMP and Costa Rican studies. Error bars indicate SEs. In the CAMP analysis exacerbation rates are over the first year of the trial, whereas in the Costa Rican analysis exacerbation rates are over the past year before entry into the study. Zero, 1 , and 2 are the genotypes AA, Aa, and aa, respectively, where a is the minor allele. Interaction $P$ values for the CAMP study are . 00536, .00175, and .00638 for rs 7941607, rs2272094, and rs2140151, respectively. For the Costa Rican study, the interaction $P$ values are $.00990, .02544$, and .02932 for rs 7941607 , rs2272094, and rs2140151, respectively. The number of subjects in each group is indicated in the figure. 
rs2272094

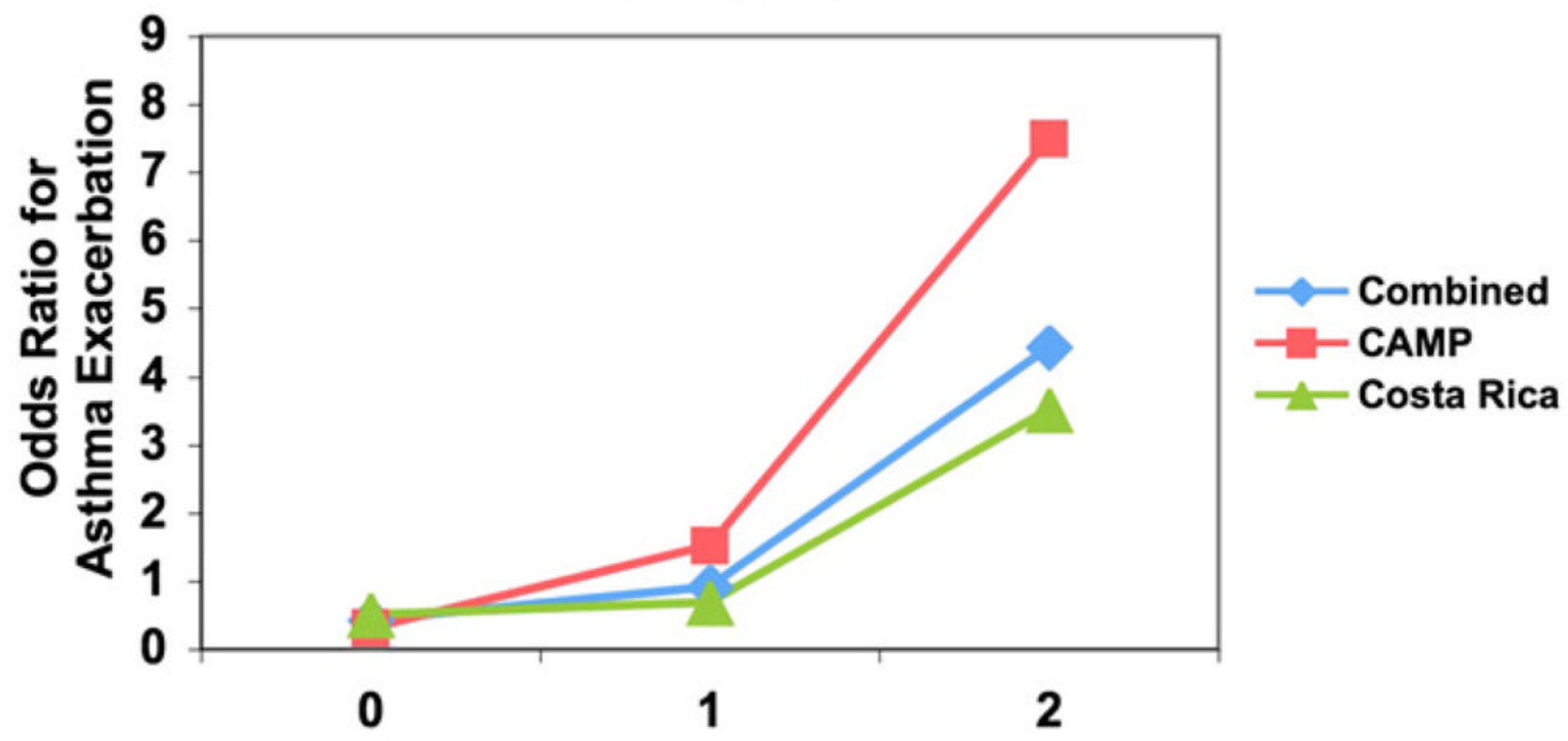

Genotype

FIG 2.

ORs for asthma exacerbation in subjects with low vitamin D levels compared with those in subjects with high vitamin D levels. Blue, Mantel-Haenszel summary OR of both the CAMP and Costa Rican populations. The number of subjects with genotypes 0,1 , and 2 are 203, 163, and 29 for the CAMP cohort and 261, 260, and 52 for the Costa Rican cohort, respectively. 


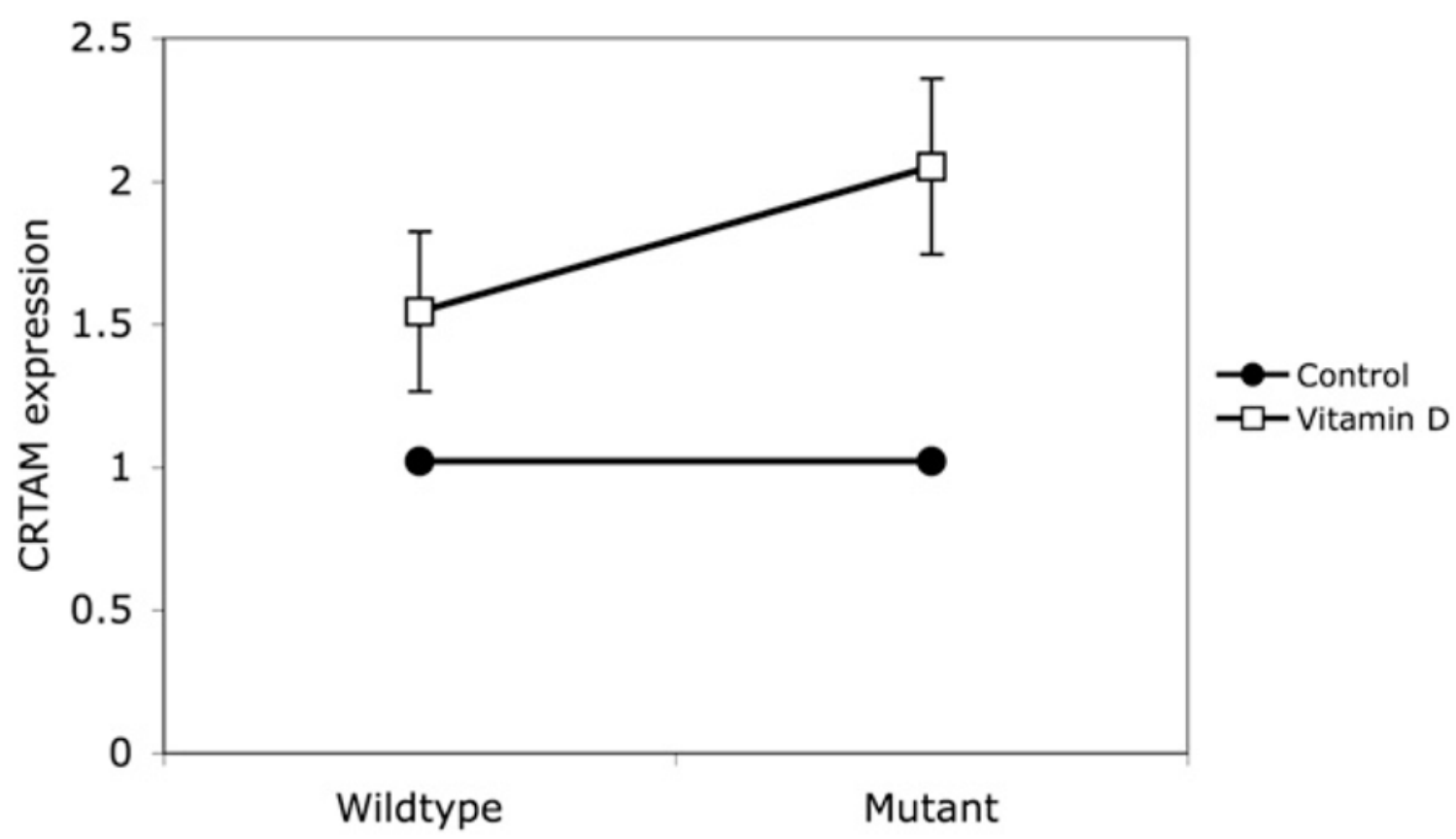

FIG 3.

CRTAM-normalized expression for cell lines homozygous in the major (Wildtype, $\mathrm{GG}, \mathrm{n}=$ 10 ) and minor (mutant, AA, $\mathrm{n}=10$ ) alleles for rs2272094 in the presence and absence of vitamin D. Ten cell lines were used in each of the 4 groups. Error bars indicate SEs. 


\section{TABLE I}

Baseline characteristics of participants in the CAMP and Costa Rican studies

\begin{tabular}{lcc}
\hline & CAMP $(\mathbf{n}=\mathbf{3 9 5})$ & Costa Rica $(\mathbf{n}=\mathbf{5 8 4})$ \\
\hline Asthma exacerbation in 1 ${ }^{*}$ & $0.14(56 / 395)$ & $0.83(482 / 584)$ \\
\hline Vitamin D level $\$ 30 \mathrm{ng} / \mathrm{mL}^{*}$ & $0.29(115 / 395)$ & $0.28(162 / 584)$ \\
\hline Female sex & $0.37(146 / 395)$ & $0.40(236 / 584)$ \\
\hline Age $(\mathrm{y})$, mean & $8.76 \pm 2.10$ & $9.03 \pm 1.84$ \\
\hline Age (y), range & $5.0-13.0$ & $6.02-14.23$ \\
\hline FEV $(\mathrm{L})$, mean & $1.63 \pm 0.46$ & $1.74 \pm 0.49$ \\
\hline $\mathrm{FEV}_{1}(\mathrm{~L})$, range & $0.42-3.14$ & $0.72-3.87$ \\
\hline $\mathrm{FEV}_{1}(\%$ predicted), mean & $93.4 \pm 13.8$ & $99.7 \pm 17.2$ \\
\hline $\mathrm{FEV}_{1}(\%$ predicted), range & $54-138$ & $35-155$ \\
\hline
\end{tabular}

Fraction of population. 


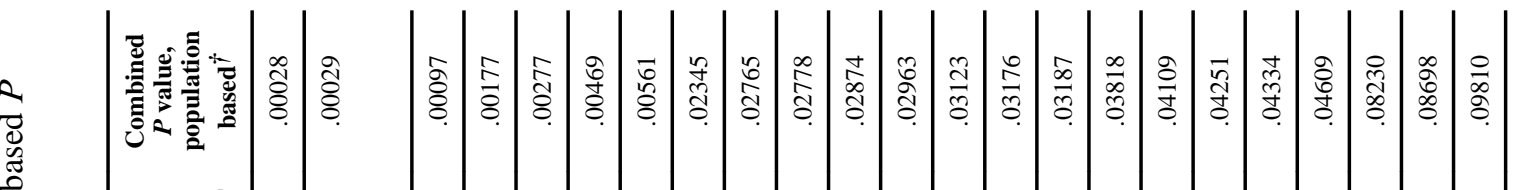

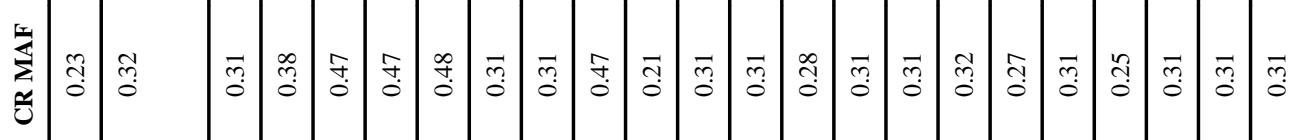

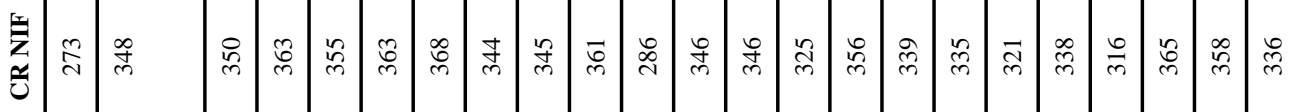

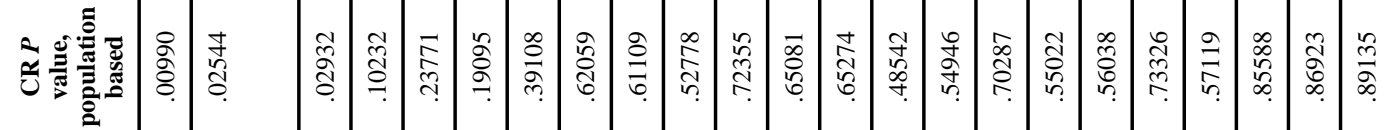

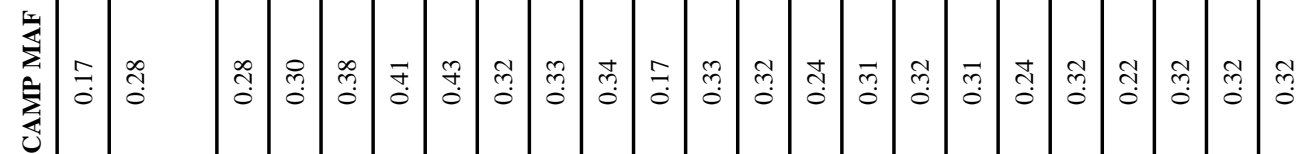

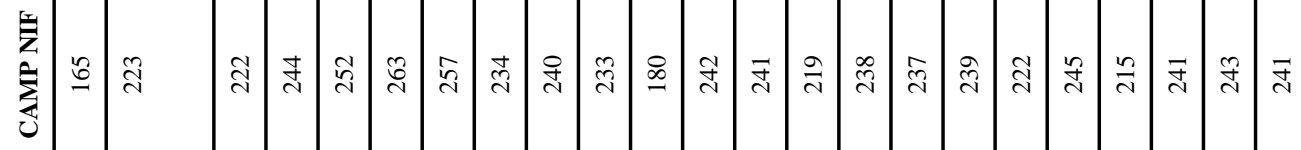

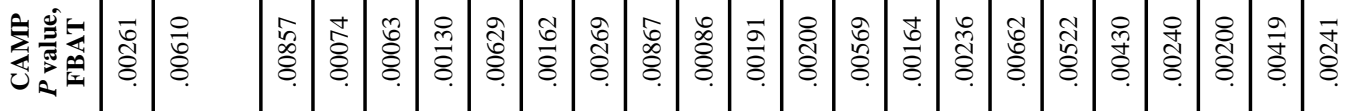

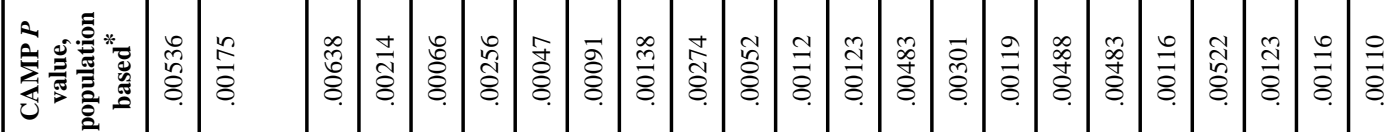

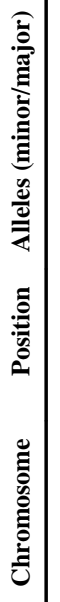

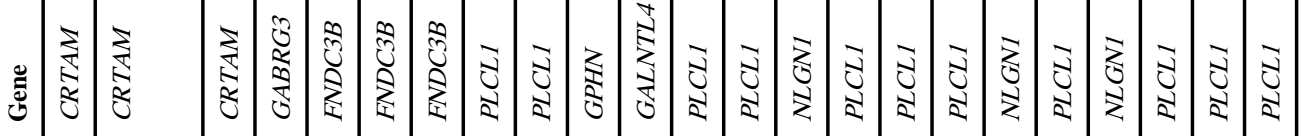

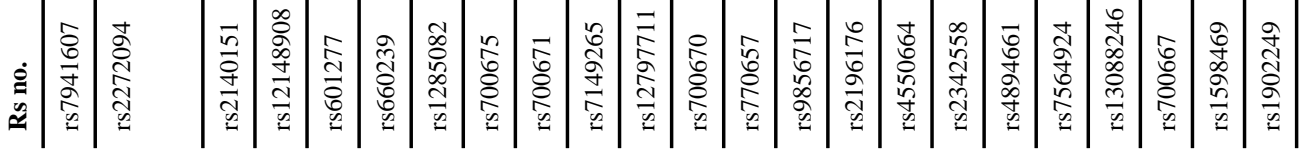




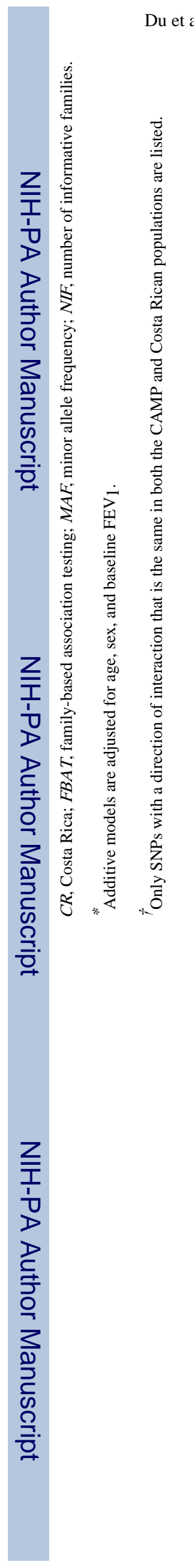

J Allergy Clin Immunol. Author manuscript; available in PMC 2013 February 01. 